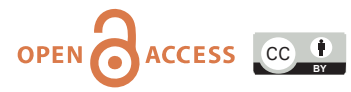

doi: $10.31729 /$ jnma.5133

\title{
Dental Floss Prescription Pattern among the Dental Interns of Nepal
}

\author{
Nashib Pandey, ${ }^{\text {S Sushmit Koju, }}{ }^{2}$ Anju Khapung, ${ }^{3}$ Sujaya Gupta, ${ }^{4}$ Deepa Aryal, ${ }^{1}$ Bhageshwar Dhami ${ }^{1}$ \\ 'Department of Periodontics, Kantipur Dental College Teaching Hospital, Kathmandu, Nepal, ${ }^{2}$ Department of Oral \\ Pathology, Kantipur Dental College Teaching Hospital, Kathmandu, Nepal, ${ }^{3}$ Department of Community Dentistry, \\ College of Dental Sciences, Nepal Medical College, Kathmandu, Nepal, ${ }^{4}$ Department of Periodontics and Oral \\ Implantology, Kathmandu Medical College, Bhaktapur, Nepal.
}

\section{ABSTRACT}

Introduction: Periodontal disease is regarded as one of the preventable diseases. It can be prevented through effective plaque control measures that require mechanical instrumentation with various surgical or non-surgical periodontal therapies as well as daily oral hygiene measures. Dental professionals must be competent enough to promote good oral health by educating patients with daily oral hygiene practice measures. In this regard, the study was designed to assess the knowledge, attitude, and practice behaviour for using as well as prescribing dental floss among the dental interns of Nepal.

Methods: An online questionnaire consisting of two sections; the first comprised of the sociodemographic and professional aspects and the second consisted of questions related to knowledge, attitude, and practice regarding the use of dental floss, and its prescription was prepared using Google forms and the link was shared. The data were analysed in Statistical Package for Social Sciences (SPSS) version 20 software.

Results: In this study, the participants were familiar with the dental floss, but many lacked awareness regarding its proper use. Ninety-nine (64.3\%) of the participants personally used dental floss. Only six $(3.9 \%)$ never prescribed it to their patients. Among those who prescribed, only 37 (25\%) always demonstrated the techniques.

Conclusions: The study indicated that many participants used dental floss, however, educating and recommending the patient about it was comparatively low. This emphasizes the need to increase the awareness and use of interdental aids among dental interns to provide good oral self-care practices for the patient.

Keywords: dental floss; interdental aids; oral hygiene; periodontitis.

\section{INTRODUCTION}

Periodontitis is a ubiquitous disease affecting over $50 \%$ of the world's adult population and increases further with age. ${ }^{1}$ Severe periodontitis, a major cause of tooth loss $^{2}$ is caused by the accumulation of a plaque biofilm at and below the gingival margin. Plaque removal and/ or control is therefore fundamentally important for the prevention of periodontal diseases.
In addition to brushing and mouth rinses, American Dental Association (ADA) recommends the use of dental floss as one of the three key hygiene practices. ${ }^{3}$ Promoting good oral health by educating patients

Correspondence: Dr. Nashib Pandey, Department of Periodontics, Kantipur Dental College Teaching Hospital, Basundhara, Kathmandu, Nepal. Email: nashibpandey@gmail.com, Phone:+977:9847033701. 
with daily oral hygiene practice measures are vital for achieving optimal effectiveness and preventing trauma. The future dentists should have adequate knowledge regarding its use, proper prescription as well as demonstration to their patient.

Hence, the present study was designed to assess the knowledge, attitude, and practice behaviour for using as well as prescribing dental floss among the dental interns of Nepal.

\section{METHODS}

A cross-sectional descriptive study using an online questionnaire was conducted among dental interns of Nepal. Interns were selected as they are on the verge of their independent dental practice which affects the patients directly in their oral health practice and maintenance. The ethical approval was obtained from the Institutional Review Committee (IRC), Kantipur Dental College and Teaching Hospital (KDCH). Data collection was carried out for four months duration (from March to June 2020). Sample size of 138 was calculated by utilising the following formula for finite population:

Sample size,

$$
n=\frac{\frac{Z^{2} p(1-p)}{e^{2}}}{1+\frac{Z^{2} p(1-p)}{e^{2} N}}
$$

$Z=1.96$ at confidence level $=95 \% ; p=0.85(85 \%)^{4}$ with Margin of error $(e)=0.05(5 \%) ; N=456$, total number of dental interns of Nepal obtained by asking the dental intern representative from 12 dental colleges of Nepal.

An online questionnaire after reviewing the pertinent literature ${ }^{4-8}$ was prepared using Google forms and a link was created. The questionnaire was pretested among dental interns of $\mathrm{KDCH}$ who were not included in the study sample. The reliability of the questionnaire was tested by Cronbach alpha and the value was found to 0.71 . Suggestions for improvement in the questionnaires were incorporated from subject experts and modified accordingly. Link to the questionnaire and a cover letter along with an informed consent form were distributed to the dental interns' representative of each dental college of Nepal. This questionnaire consisted of two sections: the first comprised of the socio-demographic and professional aspects and the second section consisted of questions related to knowledge, attitude, and practice regarding the use of dental floss and its prescription. After the completion of questionnaire, the study participants were also provided with the resources related to the use and prescription of dental floss. The data from Google forms were entered in Microsoft Excel and analysed using descriptive statistics and presented as frequency and percentages in Statistical Package for Social Sciences (SPSS) version 20 software.

\section{RESULTS}

Although the calculated sample size was 138 , a total number of 154 dental interns all over the country responded to the questionnaire whose responses were included for the analysis. The mean age of the study participants was $24.21 \pm 1.24$ years. The gender wise distribution of study participants is given in Figure 1. Majority of the participants of the study lacked proper dental floss prescription related knowledge. Distribution of study participants according to knowledge, and attitude, of using as well as prescribing dental floss are depicted in Table 1 and Table 2 respectively.

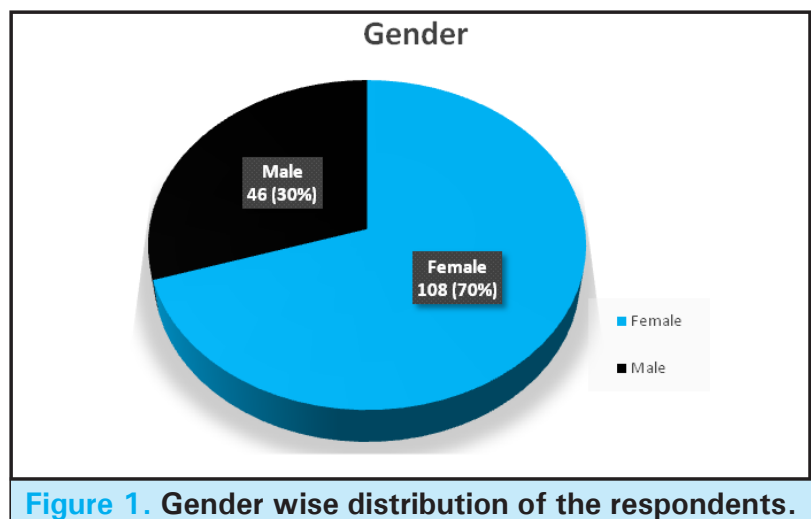

Figure 1. Gender wise distribution of the respondents. 


\begin{tabular}{|c|c|c|c|c|}
\hline Questions & Responses & $\begin{array}{l}\text { Males } \\
\text { n (\%) }\end{array}$ & $\begin{array}{l}\text { Females } \\
\text { n (\%) }\end{array}$ & $\begin{array}{l}\text { Total } \\
\text { n (\%) }\end{array}$ \\
\hline $\begin{array}{l}\text { Dental foss is prescribed } \\
\text { for }\end{array}$ & $\begin{array}{l}\text { Open contacts } \\
\text { Tight contacts } \\
\text { Both situations }\end{array}$ & $\begin{array}{l}2(4.3) \\
29(63) \\
15(32.6)\end{array}$ & $\begin{array}{l}9(8.3) \\
60(55.6) \\
39(36.1)\end{array}$ & $\begin{array}{l}11(7.1) \\
89(57.8) \\
54(35.1)\end{array}$ \\
\hline $\begin{array}{l}\text { Dental floss is prescribed } \\
\text { for removing }\end{array}$ & $\begin{array}{l}\text { Interdental plaque } \\
\text { Impacted food particles } \\
\text { Material alba } \\
\text { Debris }\end{array}$ & $\begin{array}{l}38(82.6) \\
33(71.7) \\
8(17.4) \\
20(43.5)\end{array}$ & $\begin{array}{l}75(69.4) \\
88(81.5) \\
18(16.7) \\
35(32.4)\end{array}$ & $\begin{array}{l}113(73.4) \\
121(78.6) \\
26(16.9) \\
55(35.7)\end{array}$ \\
\hline $\begin{array}{l}\text { Dental floss should be } \\
\text { prescribed }\end{array}$ & $\begin{array}{l}\text { Before brushing } \\
\text { After brushing } \\
\text { Both situations }\end{array}$ & $\begin{array}{l}12(26.1) \\
26(56.5) \\
8(17.4)\end{array}$ & $\begin{array}{l}21(19.4) \\
65(60.2) \\
22(20.4)\end{array}$ & $\begin{array}{l}33(21.4) \\
91(59.1) \\
30(19.5)\end{array}$ \\
\hline $\begin{array}{l}\text { Use of dental floss would } \\
\text { injure interdental gingiva }\end{array}$ & $\begin{array}{l}\text { Yes } \\
\text { No } \\
\text { I don't know }\end{array}$ & $\begin{array}{l}17(37) \\
15(32.6) \\
14(30.4)\end{array}$ & $\begin{array}{ll}31 & (28.7) \\
46 & (42.6) \\
31 & (28.7)\end{array}$ & $\begin{array}{l}48(31.2) \\
61(39.6) \\
45(29.2)\end{array}$ \\
\hline $\begin{array}{l}\text { Use of dental floss } \\
\text { increases the spacing } \\
\text { between teeth }\end{array}$ & $\begin{array}{l}\text { Yes } \\
\text { No } \\
\text { I don't know }\end{array}$ & $\begin{array}{l}2(4.3) \\
36(78.3 \\
8(17.4)\end{array}$ & $\begin{array}{l}10(9.3) \\
79(73.1) \\
19(17.6)\end{array}$ & $\begin{array}{l}12(7.8) \\
115(74.7) \\
27(17.5)\end{array}$ \\
\hline $\begin{array}{l}\text { Use of dental floss } \\
\text { causes gingival bleeding }\end{array}$ & $\begin{array}{l}\text { Yes } \\
\text { No } \\
\text { I don't know }\end{array}$ & $\begin{array}{ll}11 & (23.9) \\
22 & (47.8) \\
13 & (28.3)\end{array}$ & $\begin{array}{ll}26 & (24.1) \\
51 & (47.2) \\
31 & (28.7)\end{array}$ & $\begin{array}{l}37(24) \\
73(47.4) \\
44(28.6)\end{array}$ \\
\hline $\begin{array}{l}\text { Dental floss fraying } \\
\text { results during flossing } \\
\text { of proximal restoration/ } \\
\text { crown and bridges }\end{array}$ & $\begin{array}{l}\text { Yes } \\
\text { No } \\
\text { I don't know }\end{array}$ & $\begin{array}{l}23(50) \\
8(17.4) \\
15(32.6)\end{array}$ & $\begin{array}{ll}61 & (56.5) \\
22 & (20.4) \\
25 & (23.1)\end{array}$ & $\begin{array}{l}84(54.5) \\
30(19.5) \\
40(26)\end{array}$ \\
\hline
\end{tabular}

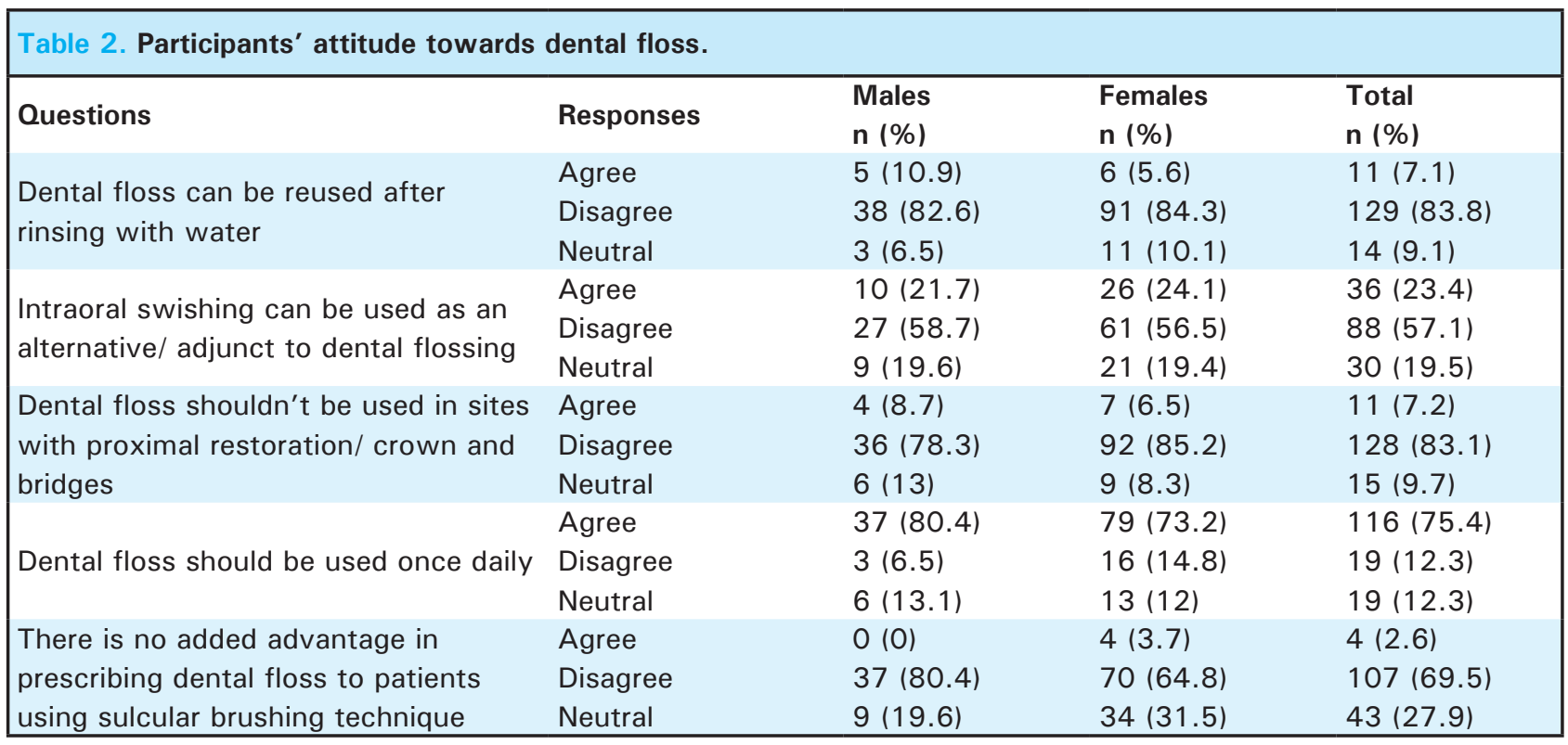


Regarding the practice, 99 (64.3\%) of them have been using dental floss personally and 148 (96\%) are prescribing it. Among the prescribers, only 37 (25\%) always demonstrated the techniques. Frequency distribution of study participants according to gender regarding their practice of using as well as prescribing dental loss is depicted in (Table 3 ).

Table 3. Participants' practice for the use and prescription of dental floss.

\begin{tabular}{|lllll|}
\hline Questions & Responses & Males & Females & Total \\
Do you personally use dental & Yes & $\mathbf{n}(\%)$ & $\mathbf{n}(\%)$ & $99(64.3)$ \\
floss? & No & $24(52.2)$ & $75(69.4)$ & $55(35.7)$ \\
Have you ever prescribed dental & Always & $22(47.8)$ & $33(30.6)$ & $27(17.5)$ \\
floss to your patients? & Sometimes & $6(13)$ & $21(19.4)$ & $121(78.6)$ \\
& Never & $35(76.1)$ & $86(79.6)$ & $6(3.9)$ \\
Do you demonstrate the & Always & $5(10.9)$ & $1(1)$ & $37(25)$ \\
technique of using dental floss to & Sometimes & $8(19.5)$ & $29(27.1)$ & $53(35.8)$ \\
your patients? & Never & $21(51.3)$ & $32(29.9)$ & $3(2.1)$ \\
& Depend upon patients & $11(26.8)$ & $44(41.1)$ & $55(37.1)$ \\
What do you prefer to & & $1(2.4)$ & & $7(4.7)$ \\
demonstrate the technique & Your own mouth & $3(7.3)$ & $4(3.7)$ & $17(15.9)$ \\
of using dental floss to your & Patients own mouth & $4(9.8)$ & $86(80.4)$ & $121(14.2)$ \\
patients? & Typhodont model & $34(82.9)$ & $(81.1)$ \\
\hline
\end{tabular}

\section{DISCUSSION}

Dental floss has been used since prehistoric times. Father of oral hygiene, Levi Spear Parmly, a dentist from New Orleans, has been credited for inventing the modern dental floss. ${ }^{9}$ In 1815 , he recommended flossing with a piece of silk thread, through the interstices of the teeth, between their necks and the arches of the gum, to dislodge that irritating matter which no brush can remove and which is the real source of disease. Since then, humble silk thread has undergone tremendous transformation in modern times. ${ }^{9,10}$ Although different varieties of floss products have been developed, any floss product in combination with a manual toothbrush can remove plaque significantly better than the toothbrush alone. ${ }^{11-12}$

Interdental cleaning aids should be professionally taught not only to patients with gingival inflammation but also to those with healthy gingiva. Specific prescription for dental floss is recommended in cases with healthy sites where attachment loss is not evident and trauma and/or increased space may result due to the improper use of interdental brushes. ${ }^{2}$ Professional instructions for using dental floss at home have much impact in preventing periodontal disease. Hence, the knowledge, attitude, and practices, for using as well as prescribing dental floss among the future dental practitioners who are about to start their professional career to identify the deficiencies are essential. This can be helpful to plan corrective measures. The present study assessed the dental floss prescription-related knowledge, attitude, and practice among dental interns of Nepal, which can be utilised in the reformation of oral health related topics of dental programs of Nepal.

In the current study, $99(64.3 \%)$ of the dental interns surveyed have been using dental floss personally. Various studies conducted across the globe have reported with the percentages of dentists using dental floss with $22 \%$ in India, ${ }^{4} 23.4 \%$ in Japan, ${ }^{5}$ and $56.3 \%$ in the US. ${ }^{6}$ The current oral hygiene practice of the prescribers may affect the prescription pattern. ${ }^{4} \mathrm{~A}$ maximum number of dental interns using dental floss as their interdental cleaning aid could have motivated them in prescribing it. It was observed that more than $96 \%$ of the dental interns had prescribed dental floss to their patients. A study conducted among the Indian dentists reported $63.9 \%$ of dentists prescribed floss routinely to their patients. ${ }^{4}$ Although, low in number, the reason for not being involved in prescribing dental floss in the start of their clinical practice might be they have not been posted in the respective department where the floss is to be prescribed. Only 37 (25\%) respondents "always" demonstrated the technique of flossing to the patients in our study, which can be attributed to the lack of demonstration of dental flossing procedure at the dental schools by their teachers as reported by Nakamura et al. ${ }^{5}$

In this study, more than $75 \%$ of the participants agreed that dental floss should be used once daily. In a study done among different health care professional in the United States, it was found that persons flossing less 
than once a day were as likely to have periodontitis as those who flossed daily $(\mathrm{OR}=1.16,95 \% \mathrm{Cl}: 0.63$ to 2.13) after controlling for the profession, age, gender, smoking, diabetes, coronary heart disease, history of periodontal surgery, and the number of teeth present. ${ }^{6}$ Another study conducted among 44 dental students of School of Dentistry, Kerman, Iran, have come with a conclusion that if a person with normal periodontal tissues uses the toothbrush and dental foss properly, using dental floss in every other day is sufficient to maintain the gingival health. ${ }^{7}$

Passing dental floss between contact areas is the most widely used method to evaluate interproximal contacts by the operator, ${ }^{13}$ but it can be prescribed for both open as well as tight contact areas. Although the interdental brush is prescribed for open contact areas, dental floss can also be prescribed if a proper technique has been demonstrated based on the patients' teeth alignment in the arch. Just prescribing dental floss is not enough; it is also essential to demonstrate correct flossing technique, as incorrect flossing may result in cervical abrasion of the teeth and angular alveolar bone loss. ${ }^{14,15}$ Several diverse factors significantly influence the way students perceive and experience their education. The improvements can be made with increased formative assessment and self-assessment opportunities, collaborative learning, familiarisation with and increased implementation of information and communication technology applications, early clinical exposure. ${ }^{16}$

In the current study, the majority of the participants 91 $(59.1 \%)$ believed that dental floss should be prescribed after brushing. However, in a Randomised Controlled Clinical Trial, researchers have found that the amount of plaque between the teeth and in the mouth overall was significantly reduced when participants used the floss before brushing. They contend that as flossing loosens bacteria and debris from between the teeth, brushing afterward (when the mouth is rinsed with water) further clears the mouth of these particles. ${ }^{8}$

Various myths related to dental floss among the patients like it increases bleeding gums, and spacing between teeth was not prevalent in the majority of the study population. We had asked the participants about intraoral swishing. "Can, intraoral swishing be used as an alternative/ adjunct to dental flossing?" The majority $(88,57 \%)$ of the participants didn't agree on this note. The much-overlooked procedure of swishing of water after the consumption of foods and soft drinks can be a safe, economic and easy means of improving oral hygiene in addition to tooth brushing. ${ }^{17}$ Swishing 20-30 ml of water after eating food or consumption of soft drinks and also between meals for two to five minutes can be of help in the removal of loosened food particles, dead cells and mucous from the oral cavity. ${ }^{18}$ Warming the water and adding a pinch of table salt reduces inflammation and can be microbicidal because of its high osmolality. ${ }^{19}$ Studies have even revealed that oral irrigation is an effective alternative to manual tooth brushing and dental flossing for reducing bleeding and gingival inflammation. ${ }^{20}$ Dental waterjets in the form of commercially available water flosser (e.g., Waterpik) and mouthwashes are expensive but vigorous water swishing using movement of the lips, tongue, cheeks can be a beneficial alternative for goodoral hygiene. ${ }^{17}$ Various literature supporting the efficacy of commercially available water flosser can be found abundantly ${ }^{21-25}$ but very few have mentioned about the role of vigorous water swishing using the movement of the lips, tongue, cheeks. This may be because of the commercial interest of the manufacturers. The low number of evidence for Water swishing has been reflected in the knowledge of dental interns of Nepal as well. Future research can be directed towards comparing the efficacy of vigorous water swishing using the movement of the lips, tongue, cheeks with other interdental aids.

Checking practical demonstrations along with a selfreported questionnaire rather than just a questionnaire could have given us with the actual practice status of dental interns. Initially, during the proposal development, the study was designed to check the steps of flossing in a typhodont model along with the questionnaire. But, because of the COVID-19 lockdown imposed by the government of Nepal during the data collection period, we faced difficulty in reaching each dental intern in person. So the demonstration part was not carried and IRC was informed about this. Future studies related to dental floss practice can be conducted by incorporating the demonstration part as well. The authors would like to recommend that similar study can be conducted among other dental professionals as well as the general population to understand the need and practices of dental floss.

\section{CONCLUSIONS}

The results obtained from the present study indicate the necessity of motivating the students and interns to follow self-oral hygiene practices and also educate the patients regarding the same. Though many participants use dental floss, it was seen that educating and recommending the patient about it was comparatively low. This emphasizes the need to increase the awareness and use of aids among dental interns to provide good oral self-care practices for the patient. Patient education through practical demonstration of dental floss use should be made compulsory to the dental interns so that they can increase their confidence level in demonstrating it to the patients. 


\section{ACKNOWLEDGEMENTS}

The authors would like to thank all the dental interns who participated in our study. We also would like to thank Dr. Arjun Hari Rijal, Dr. Nisha Maharjan, Dr.
Kamana Neupane, Dr. Sunita Khanal, and Dr. Sujita Shrestha, for their support in the completion of this study.

\section{Conflict of Interest: None.}

\section{REFERENCES}

1. Petersen PE, Ogawa H. The global burden of periodontal disease: towards integration with chronic disease prevention and control. Periodontol 2000. 2012;60(1):15-39. [PubMed | Full Text | DOI]

2. Chapple IL, Van der Weijden F, Doerfer C, Herrera D, Shapira L, Polak D, et al. Primary prevention of periodontitis: managing gingivitis. J Clin Periodontol. 2015;42 Suppl 16:S71-6. [uued | Full Text | DOI]

3. American Dental Association. Floss/Interdental Cleaners [Internet]. Department of Scientific Information, Evidence Synthesis and Translation Research, ADA Science and Research Institute, LLC [updated 2019 March 25; cited 2020 Jan 19]. Available from: https://www.ada.org/en/ member-center/oral-health-topics/floss\# [ Full Text]

4. Madan C, Arora K, Chadha VS, Manjunath BC, Chandrashekar BR, Rama Moorthy VR. A knowledge, attitude, and practices study regarding dental floss among dentists in India. J Indian Soc Periodontol. 2014;18(3):361-8. [PubMed | Full Text | DOI]

5. Nakamura F, Hirayama Y, Morita I, Nakagaki H. Factors associated with Japanese dentists encouraging patients to use dental floss. Community Dent Health.. 2011;28:111-5. [Full Text $\mid \underline{\text { PubMed] }}$

6. Merchant A, Pitiphat W, Douglass CW, Crohin C, Joshipura K. Oral hygiene practices and periodontitis in health care professionals. J Periodontol. 2002;73(5):531-5. [ㅁuMed | Full Text $\mid \underline{\text { DOI] }}$

7. Shamsaddin H, Motamedi A. How many times is the optimum dental floss frequency in people with normal periodontium? A randomized controlled single blind clinical trial. J Oral Health Oral Epidemiol. 2015;4(2):59-63. [Full Text]

8. Mazhari F, Boskabady M, Moeintaghavi A, Habibi A. The effect of toothbrushing and flossing sequence on interdental plaque reduction and fluoride retention: A randomized controlled clinical trial. J Periodontol. 2018;89(7):824-32. [PubMed $\mid$ Full Text $\mid \underline{\text { DOI] }}$

9. Sanoudos M, Christen AG. Levi Spear Parmly: The apostle of dental hygiene. J Hist Dent. 1999;47(1):3-6. [ PubMed | Full Text]

10. Chernin D, Shklar G. Levi Spear Parmly: Father of dental hygiene and children's dentistry in America. J Hist Dent. 2003;51(1):15-8. [PubMed | Full Text]
11. Terézhalmy GT, Bartizek RD, Biesbrock AR. Plaque-removal efficacy of four types of dental floss. J Periodontol. 2008;79(2):245-51. [ㄹuMed | Full Text | DOI]

12. Worthington HV, MacDonald L, PoklepovicPericic T, Sambunjak D, Johnson TM, Imai P, et al. Home use of interdental cleaning devices, in addition to toothbrushing, for preventing and controlling periodontal diseases and dental caries. Cochrane Database Syst Rev. 2019;(4) Art: CD012018. [ PubMed | Full Text | DOI]

13. Teich ST, Joseph J, Sartori N, Heima M, Duarte S. Dental floss selection and its impact on evaluation of interproximal contacts in licensure exams. J Dent Educ. 2014;78(6):921-6. [PubMed $\mid \underline{\text { Full Text } \mid \text { DOI] }}$

14. Walters JD, Chang EI. Periodontal bone loss associated with an improper flossing technique: A case report. Int J Dent Hyg. 2003;1:115-9. [PubMed | Full Text | DOI]

15. Salas ML, McClellan AC, MacNeill SR, Satheesh KM, Cobb CM. Interproximal cervical lesions caused by incorrect flossing technique. Int J Dent Hyg. 2012;10:83-5. [라Med | $\underline{\text { Full Text }}$ DOI]

16. Divaris K, Barlow PJ, Chendea SA, Cheong WS, Dounis A, Dragan IF, et al. The academic environment: the students' perspective. Eur J Dent Educ. 2008;12 Suppl 1:120-30.

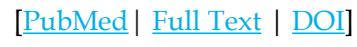

17. Math $M$, Balasubramaniam P. Water swishing. Br Dent J. 2009;207(7):304. [ PubMed | Full Text | DOI]

18. Math MV, Balasubramaniam P. Oral health and water. Indian J Nutr Diet. 2008; 45(9):388-91. [Full Text]

19. Malik R. Warm saline rinses. Br Dent J. 2009;207(11):520. [ $\underline{\text { PubMed }}|\underline{\text { Full Text }}| \underline{\text { DOI}}]$

20. Barnes CM, Russell CM, Reinhardt RA, Payne JB, Lyle DM. Comparison of irrigation to floss as an adjunct to tooth brushing: effect on bleeding, gingivitis, and supragingival plaque. J Clin Dent. 2005;16(3):71-7. [PubMed | Full Text ]

21. Goyal CR, Qaqish JG, Schuller R, Lyle DM. Evaluation of the Addition of a Water Flosser to Manual Brushing on Gingival Health. J Clin Dent. 2018;29(4):81-6. [uuMed]

22. Lyle DM, Goyal CR, Qaqish JG, Schuller R. Comparison of water flosser and interdental brush on plaque removal: a single-use pilot study. J Clin Dent.. 2016;27(1):23-6. [ubMed]

23. Goyal CR, Lyle DM, Qaqish JG, Schuller R. Comparison of Water Flosser and Interdental Brush on Reduction of Gingival Bleeding and Plaque: A Randomized Controlled Pilot Study. J Clin Dent. 2016;27(2):61-5. [․ubMed] 
24. Goyal CR, Lyle DM, Qaqish JG, Schuller R. Efficacy of Two Interdental Cleaning Devices on Clinical Signs of Inflammation: A Four-Week Randomized Controlled Trial. J Clin Dent. 2015;26(2):55-60. [PubMed]
25. Lyle DM, Qaqish JG, Goyal CR, Schuller R. Efficacy of the Use of a Water Flosser in Addition to an Electric Toothbrush on Clinical Signs of Inflammation: 4-Week Randomized Controlled Trial. Compend ContinEduc Dent. 2020;41(3):170-7. [ubMed | Full Text ] 